\title{
Predictors of Bronchopulmonary Dysplasia
}

\author{
Andrea Trembath, MD, MPH ${ }^{1}$ and Matthew Laughon, MD, MPH ${ }^{1}$ \\ ${ }^{1}$ Division of Neonatal-Perinatal Medicine, The University of North Carolina at Chapel Hill, Chapel \\ Hill, NC
}

\section{Keywords}

bronchopulmonary dysplasia; predictors/risk factors; chronic lung disease; mechanical ventilation

\section{Introduction}

Although significant advances in respiratory care have been made in neonatal medicine, bronchopulmonary dysplasia (BPD) remains the most common serious pulmonary morbidity in premature infants. Premature infants with BPD have a longer initial hospitalization than their peers without $\mathrm{BPD}^{1}$ and $\mathrm{BPD}$ remains a substantial lifelong burden. The costs of the disorder are both social and economic and are measured in impaired childhood health and quality of life, family stress and economic hardship, and increased healthcare costs. ${ }^{2-4}$

Over the last 40 years the definition, the disease, and the risk factors for BPD have changed. ${ }^{5,6}$ BPD, as it was initially described by Northway in the 1960's, was based on clinical and radiographic evidence of pulmonary disease in moderately to late premature infants with a history of respiratory distress syndrome. ${ }^{7}$ The respiratory management of these infants included exposure to prolonged mechanical ventilation and oxygen exposure. On histological samples, the characteristic areas of hyperinflation alternating with areas of focal collapse were often noted, as well as hyperplasia of the bronchial epithelium. ${ }^{8}$ Radiography of these infants showed areas of heterogeneity throughout the lung fields and coarse scattered opacities in the most severely affected of infants. ${ }^{9}$

The 'classical' BPD described by Northway has been replaced by a milder form of the disease. There is reason to believe that risk factors associated with the "new" BPD, compared to historical risk factors, may be distinct. This "new" BPD occurs in less mature infants exposed to antenatal steroids, who are often treated with exogenous surfactant therapy. They spend fewer days on positive pressure ventilation and have less exposure to supplemental oxygen. Animal studies suggest that the histology of "new" BPD shows more diffuse disease, fewer areas of hyperinflation, a reduction in alveoli and capillaries, but little fibrosis. ${ }^{10,11}$

The incidence of BPD varies widely between centers even after adjusting for potential risk factors. Data from 2010 from the Vermont Oxford Network shows the rates of BPD vary from $12 \%$ to $32 \%$ among infants born less than 32 weeks gestation. Although there have been multiple trials aimed at reducing the incidence of BPD, it seems that the incidence is

(C) 2012 Elsevier Inc. All rights reserved.

Publisher's Disclaimer: This is a PDF file of an unedited manuscript that has been accepted for publication. As a service to our customers we are providing this early version of the manuscript. The manuscript will undergo copyediting, typesetting, and review of the resulting proof before it is published in its final citable form. Please note that during the production process errors may be discovered which could affect the content, and all legal disclaimers that apply to the journal pertain. 
stagnant, or even increasing. The rising absolute number of infants with BPD might be due to the improvement in the survival of extremely low gestational age infants, the population most likely to carry this diagnosis. $5,12,13$ Compared with the pathology described by Northway, the most common type of BPD today may be a less severe form of the disease.

This chapter will review the definitions of BPD, and the predictors of BPD by time period (before, at, and after birth). In addition, several of the estimators that are available to quantify the risk of BPD, and explain how this might affect clinicians, families, and researchers are reviewed.

\section{Defining BPD}

The definition of BPD most often uses receipt of oxygen therapy or positive pressure for a duration of time (usually in days) or on a specific day (e.g. postnatal day 28 or at postmenstrual age 36 weeks). The original definition was based on receipt of oxygen at 28 days of age. However, this definition does not take into account the various developmental considerations of infants born across the spectrum of susceptible gestational ages. Thus, attempts have been made to improve the definition through a corrected age "cutpoint", most commonly the need for supplemental oxygen therapy at 36 weeks PMA. The NICHD divided the definition further using a severity scale. Since oxygen saturation targets vary from center to center, a "physiologic definition" has been proposed as well. These definitions are reviewed in more detail below.

A workshop to clarify the definition of BPD was held by the National Institute of Child Health and Human Development in June 2000 with the goal to distinguish BPD from chronic lung disease (CLD), a condition that was felt to represent a group of heterogeneous diseases occurring later in life. ${ }^{14}$ This workshop proposed a severity-based definition that classified BPD as mild, moderate or severe based on either postnatal age or PMA (Table 1). Mild BPD was defined as a need for supplemental oxygen $\left(\mathrm{O}_{2}\right)$ throughout the first 28 days but not at 36 weeks PMA or at discharge; moderate BPD as a requirement for $\mathrm{O}_{2}$ throughout the first 28 days plus treatment with $<30 \% \mathrm{O}_{2}$ at 36 weeks PMA; severe BPD as a requirement for $\mathrm{O}_{2}$ throughout the first 28 days plus $\geq 30 \% \mathrm{O}_{2}$ and/or positive pressure at 36 weeks PMA. Ehrenkranz et al ${ }^{15}$ validated the NICHD severity-based definition of BPD by comparing it to the more traditional definitions of BPD such as supplemental oxygen at 28 days and at 36 weeks PMA. The consensus NICHD severity-based scale better identified infants who are at most risk for poor pulmonary outcomes as well as neurodevelopment impairment than the traditional definitions. ${ }^{15}$

The physiologic definition of BPD was developed by Walsh, et al ${ }^{16}$ and defines BPD as a failure to maintain a saturation value $>90 \%$ when challenged with $21 \%$ oxygen at 36 weeks PMA. Unit-specific rates of BPD using the physiologic-definition were compared to rates of BPD using the traditional definition of BPD (oxygen need at 36 weeks PMA) for premature infants weighing 501-1249 grams. The physiologic definition reduced the between center variability in the diagnosis of BPD and reduced the diagnosis as much as 10\% at individual centers. The physiologic definition has also been validated and shown to be independently predictive of cognitive impairment in infants with BPD. ${ }^{17}$ The physiologic definition is used by the NICHD Neonatal Research Network centers throughout the United States.

Regardless of which definition of BPD one uses, a period of time is required before the definition is made. This makes identifying therapies for premature infants at risk of BPD challenging. An infant born at 23-weeks gestation who needs mechanical ventilation at 34 weeks postmenstrual age is likely to develop BPD, as defined as oxygen therapy at 36 weeks. That infant may benefit from strategies that improve short-term outcomes, but which do not reduce the incidence of BPD. For example, in a Cochrane Systematic Review, 
Stewart et al. found the use of diuretics may transiently improve oxygenation and pulmonary function, but did not reduce the development of BPD (RR 0.80 (95\% CI: 0.18, 3.54). ${ }^{18}$ Recently, a prototype "Proxy Reported Pulmonary Outcome Score (PRPOS) has been developed to define nuances in pulmonary function as reported by caregivers. The PRPOS consists of 26 observations that can be made by a nurse before, during and after providing routine care and feeding. ${ }^{19}$ The goal is to make assessments about functional domains of infants that will help to discriminate between infants with none, mild, moderate and severe pulmonary dysfunction. This novel approach might allow testing of therapies (such as diuretics) aimed at improving pulmonary outcomes that do not require waiting for the development of an outcome several days or weeks later.

\section{Understanding and interpreting the predictors of BPD?}

Predictors of disease are more commonly known as risk factors. In epidemiologic studies, risk is most often used synonymously with probability of disease occurrence, however it may represent a wide variety of statistical measures that include incidence, prevalence, rate or odds. A risk factor often implies an increase in the outcome of interest with exposure, although risk measures may also represent protective effects. ${ }^{20}$

In many studies, risks are often compared through relative measures - risk ratio, odds ratio or rate ratio. ${ }^{21}$ Relative measures are helpful for identifying risk factors, but can be misleading when not accompanied by absolute measures such as the risk difference. For example a relative risk of 2.0 indicates that the exposed group is twice as likely to develop the disease as the unexposed group. However, twice as likely may represent an absolute change in risk from $0.2(20 \%)$ to $0.1(10 \%$; risk difference of 0.1 or $10 \%)$ or may represent an absolute change in risk from $0.002(0.2 \%)$ to $0.001(0.1 \%$; risk difference of 0.001 or $0.1 \%)$. This is important because small changes in absolute risk differences might not be as amenable to change as a large risk difference.

Attributable risk proportion (ARP), also known as the etiologic fraction, represents the proportion of the incidence of disease among exposed persons that is due to the exposure. The ARP is often useful when identifying risk factors in diseases such as BPD that are multi-factorial. As with all risk measures, however, caution should be used when inferring causality. ${ }^{22}$ Most diseases such as BPD have many component causes, some of which remain either unknown or immeasurable. These component causes can occur at different times and the sequence of their occurrence may be important in the development of the disease. In addition, risk measures cannot distinguish a necessary cause from a component cause. Removal of a single component cause can reduce disease burden, but removal of a necessary cause may prevent the disease entirely. ${ }^{23}$ Several studies have demonstrated that the retrospective examination of risk factors for BPD alone is difficult given the interrelation of true risk factors, the difficulty in distinguishing temporal relationships and confounding factors. ${ }^{24-26}$

Traditionally, researchers identified risk factors for BPD by categorizing premature infants as having or not having BPD, using one of the definitions noted above, and then retrospectively examining all factors that influenced risk up to the time of diagnosis. As a result, each study has reached different conclusions regarding the risk factors for the development of BPD. In addition, most used some type of multivariate modeling in an attempt to adjust for potential confounders and effect modifiers (e.g. by adjusting for gestational age).

For examples, in a study by Rojas et $\mathrm{al}^{27}$ risk factors for BPD in ventilator-supported preterm infants weighing between 500 and $1000 \mathrm{~g}$ included low birth weight, presence of a patent ductus arteriosus (PDA) and sepsis. Of these infants, $37 \%$ had a diagnosis of BPD as 
defined as oxygen therapy at 28 days. In contrast Marshall et a ${ }^{24}$ defined risk factors for $\mathrm{BPD}$ as nosocomial infection, magnitude of fluid intake on day 2, PDA and need for ventilation at 48 hours of life. Of the 1244 infants between 500-1500 g included in the study $26 \%$ developed CLD, defined as dependency on supplemental oxygen at 36 weeks postmenstrual age. In a secondary analysis of the Neonatal Research Network Glutamine trial, the risk factors for infants who died or developed BPD (defined as oxygen therapy at 36 weeks PMA) were lower birth weight and gestational age, male sex, lower 1 and 5minute Apgar Scores, higher oxygen requirement at 24 hours of age, longer duration of assisted ventilation, use of postnatal steroids, severe intraventricular hemorrhage, necrotizing enterocolitis, patent ductus arteriosus, and late onset sepsis. ${ }^{25}$ In preterm infants with respiratory failure enrolled in the Neonatal Research Network inhaled nitric oxide trial, the authors found that the risk of death or BPD was associated with lower birth weight, higher oxygen requirement, male gender, additional surfactant doses, higher oxygenation index and outborn status. ${ }^{26}$ These examples demonstrate that in multifactorial diseases, such as BPD, multiple definitions as well as confounding in retrospective studies can distort the exposure-outcome relationship.

\section{Risk factors before birth}

\section{Antenatal Steroids}

Antenatal steroids are associated with a decrease in severity of respiratory distress syndrome and neonatal mortality. ${ }^{28,29}$ As a result, antenatal steroids were initially believed to decrease the risk of BPD. ${ }^{30}$ In a study by Van Marter et al. using multivariate analysis, the independent effect of antenatal steroids on the risk of BPD was examined. They found that treatment with either a partial or full course of antenatal steroids did not convey any additional benefit in reducing the likelihood of BPD after adjustment for other important confounders such as gestational age, infection and respiratory management strategies (OR $0.9895 \%$ CI: 0.66, 1.5). In a Cochrane analysis that included 818 infants from 6 studies, the risk of BPD (defined as oxygen at 36 weeks PMA) was not significantly different between infants who were exposed to antenatal steroids as compared to controls (RR $0.86,95 \%$ CI: $0.61,1.22)$. Overall these studies suggest that antenatal steroid exposure does not modify the risk of BPD; however, this may be due to an increase in survival of the most immature antenatal steroid-exposed infants.

\section{Chorioamnionitis}

Chorioamnionitis is one of the leading causes of very preterm delivery. The association between chorioamnionitis and BPD is difficult to assess as the diagnosis has several definitions. A clinical diagnosis of chorioamnionitis is commonly made based on maternal symptoms and is subject to significant variability between providers. Furthermore, clinical chorioamnionitis may only reflect acute inflammatory changes. Histologic evidence of chorioamnionitis is the 'gold standard' and may reflect chronic infection but placental pathology is not always available. Antenatal inflammation, such as chorioamnionitis, has been associated with an increased rate of lung maturation. ${ }^{31}$ In a retrospective study by Dempsey et al of 392 infants born at less than 30 weeks PMA, histologic chorioamnionitis was associated with a higher incidence of premature deliveries and an increased risk of sepsis. ${ }^{32}$ However, chorioamnionitis was also associated with a significant decrease in the incidence of RDS (OR 0.43 , p-value $=0.001$ ), a finding that has been repeatedly demonstrated in multiple other studies.

The presence of chorioamnionitis is also associated with a disturbance in the normal lung maturation and growth that may have an effect on the development of BPD. ${ }^{33-35} \mathrm{~A}$ recent meta-analysis suggested that even when adjusted for other confounding factors there still 
remains an association between chorioamnionitis and an increased risk for BPD. ${ }^{36}$ However, other studies aimed at identifying predictive factors for the development of BPD using a histologic diagnosis suggest that there may be no true association with chorioamnionitis. ${ }^{37,38}$

\section{Fetal Growth Restriction}

Fetal growth restriction, defined as a birth weight less than 1 standard deviation below the median, is associated with an increased risk of BPD among premature infants. In a study by Bose et al, characteristics and potential risk factors for BPD were evaluated among 1241 infants enrolled in the ELGAN study. ${ }^{37}$ The authors examined the role of prenatal factors, such as preeclampsia and fetal indications for delivery, the microbiology and histology of the placenta and neonatal characteristics including fetal growth restriction (FGR). Among these infants, FGR was highly predictive of the development of BPD in all gestational ages except the lowest (23-24 weeks), after adjustment. The investigators speculated that the biologic mechanisms leading to FGR also lead to vulnerability of the developing lung, rendering infants with FGR at higher risk for the development of BPD.

\section{Risk factors at birth}

\section{Infant demographics: gestational age, birth weight, and sex}

Extreme prematurity and extremely-low-birth-weight have been well established as risk factors for BPD. Gestational age and birth weight are inversely proportional to the incidence of BPD, as well as the severity of the disease. Among infants meeting the physiological definition of BPD at $36 \mathrm{wk}$ postmenstrual age (PMA), 95\% are very-low-birth-weight (VLBW). ${ }^{16}$ In the NICHD network, the incidence of BPD at 23 weeks PMA (as defined as oxygen at 36 weeks PMA) was $73 \%$ with $56 \%$ of infants having severe BPD. In comparison, at 28 weeks PMA the incidence of BPD was $23 \%$ with only $8 \%$ of infants with severe BPD. ${ }^{39}$ Male infants have a higher risk of developing BPD as compared to females. ${ }^{27,37,40}$

\section{Risk factors after birth}

\section{Respiratory patterns}

Describing the early respiratory patterns of ELGANs may provide insight into early risk factors for BPD. Among ELGANs, three distinct patterns of lung disease typically emerge in the first two weeks of life. ${ }^{41-45}$ The first pattern includes infants with relatively little lung disease, who progressively recover. The second group of infants experience early persistent pulmonary dysfunction (EPPD) and require significant and prolonged respiratory support from birth. The third group experiences an initial improvement in their lung disease in the first week of life, followed by a respiratory decompensation that often requires mechanical ventilation and an increase in supplemental oxygen. This group is described as having pulmonary deterioration (PD).

Almost half of infants who have PD develop BPD, which makes PD an important early marker. ${ }^{46}$ The characteristics and exposure history of infants from the ELGAN study were evaluated for associations with PD. Of the 1340 infants who were enrolled $~ 40 \%$ developed pulmonary deterioration. Risk factors that may contribute to PD include late surfactant deficiency ${ }^{47}$, sepsis, and PDA. The authors found that the most important markers of PD were lower gestational age, lower birth weight, increased severity of illness (as defined as neonatal acute physiology II score) and need for higher levels of respiratory support. Other factors previously associated with PD, including male sex, multiple pregnancy, cesarean section, antenatal steroids and infection were not statistically significant in multivariate regression models. ${ }^{41,44}$ Among infants who had rapid resolution of their respiratory disease, 
$17 \%(\mathrm{n}=249)$ developed BPD (defined as supplemental oxygen at 36 weeks) compared to

$51 \%(\mathrm{n}=484)$ in infants with PD and 67\% ( $\mathrm{n}=576)$ among infants with EPPD. (Figure 1)

\section{Mechanical ventilation}

Mechanical ventilation is life saving for premature infants with respiratory failure. However, mechanical ventilation uses positive pressure that produces ventilator initiated lung injury. ${ }^{48,49}$ The development of surfactant therapy led to many extremely premature infants receiving obligatory mechanical ventilation following surfactant replacement therapy. However, reports emerged about substantial differences in BPD rates; infants born in centers that used mechanical ventilation more frequently had a higher risk of BPD. ${ }^{50,51}$ For example, the risk of BPD ranges from $<10 \%$ to $>40 \%$ among the Neonatal Research Network centers in infants $<1250$ grams birth weight. ${ }^{52}$ This variation is not explained by differences in birth weight, gestational age, race, frequency of prenatal steroid use, or incidence of respiratory distress syndrome.

Avoidance of mechanical ventilation might decrease the risk of lung injury and BPD, and might explain some of the center-to-center differences in BPD rates. ${ }^{51}$ Mechanical ventilation often begins shortly after birth; therefore delivery room management strategies might influence the risk of BPD. ${ }^{53,54} \mathrm{~A}$ full review of delivery room management and BPD is presented in another chapter in this volume. The use of nasal continuous positive airway pressure (CPAP) appears to be a successful strategy for avoiding the need for mechanical ventilation in some infants, with the presumptive benefit of decreasing the risk of BPD..$^{55}$

\section{Postnatal steroids}

The use of corticosteroids for the prevention or treatment of BPD has been examined in numerous clinical trials. Two Cochrane reviews provide information about the effect of treatment with systemic steroids on the incidence of CLD. Early treatment was defined as beginning before postnatal day eight ${ }^{56}$; late treatment was defined as beginning after seven days of postnatal age. ${ }^{57}$ Twelve trials examined the neurodevelopmental impact of early corticosteroids and demonstrated an increase in the risk of cerebral palsy (RR 1.45, 95\% CI $1.06,1.98$ ), with impairment of motor function a risk associated with early treatment. Benefits of late treatment included decreased risks of BPD at both 28 days and at 36 weeks PMA (RR 0.72, 95\% CI 0.61, 0.85) and death or CLD at 28 days and at 36 weeks PMA (RR $0.72,95 \% \mathrm{CI} 0.63,0.82$ ). There was an increased risk of abnormal neurological examination, but not an increase in neurosensory impairment or cerebral palsy.

The Dexamethasone: A Randomized Trial (DART) study identified patients at high risk for BPD based on gestational age or birth weight ( $<28$ weeks PMA or $<1000 \mathrm{~g})$ and the need for mechanical ventilation after postnatal day $7 .{ }^{58}$ Study infants were randomized to dexamethasone or placebo. $60 \%$ of those who received dexamethasone (21 of 35) were extubated by the $10^{\text {th }}$ day of treatment as compared to $12 \%$ (4 of 34) in the placebo group. Rates of mortality before follow-up, major disability, cerebral palsy, or the combined outcomes of death or cerebral palsy were not substantially different between groups. Furthermore, the incidence of BPD was $85 \%$ in the dexamethasone group and $91 \%$ in the placebo group. ${ }^{59}$

For infants at high risk of developing BPD, corticosteroids might reduce the risk of BPD and CP. In a meta-regression analysis, Doyle et $\mathrm{al}^{60}$ reviewed the results of available randomized, controlled trials of postnatal corticosteroids and determined the risk of BPD and cerebral palsy (CP) in the control groups. They found that the risk of CP increased with the use of corticosteroids, however there was significant effect measure modification among 
the groups with BPD. As the risk of BPD increased (>65\%), postnatal steroids reduced the risk of death or $\mathrm{CP}$.

\section{Patent ductus arteriosus}

The role of the patent ductus arteriosus (PDA) in the development of BPD in preterm infants remains controversial. The presence of a PDA has been associated with the need for prolonged mechanical ventilation, increased mortality and a higher risk of BPD. ${ }^{61,62}$ However, the relationship between PDA and BPD is often distorted by confounding factors such as gestational age and illness severity and might not be causal.

In a randomized clinical trial by Schmidt et al (Trial of Indomethacin Prophylaxis in Preterms (TIPP)), infants who received indomethacin prophylaxis had a decreased incidence of PDA ( $21 \%$ vs $49 \%$, p-value $<0.05$ ), however the incidence of BPD was similar between groups ( $45 \%$ vs $43 \%$, p-value 0.41$).{ }^{63}$ Indomethacin prophylaxis in this cohort increased the supplemental oxygen use from day 3 to day 7 , decreased urine output during the first 4 days of life, and reduced weight loss by the end of the first week of life. Among infants who did not develop a PDA following prophylactic indomethacin, treatment was associated with a higher incidence of BPD (43\% vs $30 \%$ p-value 0.015 ). These finding suggest that the early side effects of indomethacin may contribute to the increased risk of BPD in the treatment group.

Even when non-pharmacologic therapies are used to close the PDA the risk for BPD is increased among treated infants. In a randomized trial of prophylactic PDA ligation among infants weighing less than $1000 \mathrm{~g}$, Clyman et al. found an increased incidence of BPD (defined as supplemental oxygen at 36 weeks) and need for mechanical ventilation at 36 weeks among infants who underwent surgical ligation within 24 hours of birth. ${ }^{64}$ In addition, the development of BPD in the control group was confined to infants who ultimately needed surgical ligation (after 24 hours). They concluded that closure of the PDA via surgical ligation increases the risk of BPD.

Prior studies to assess the role of ductal closure in the prevention of morbidities such as BPD have had small sample sizes. Meta-analysis has consistently shown no decrease in the risk of BPD with closure of the PDA. ${ }^{65-67}$ In a recent systematic review, Benitz reviewed all available randomized controlled trials to create a pooled point estimate for the associations between PDA closure and multiple morbidities. The pooled estimate showed a strong effect of ductal closure with pharmacologic therapies (OR 0.23, 95\% CI 0.20, 0.26), however a non-significant effect on the incidence of BPD and BPD or death. ${ }^{68}$ It is likely that the presence of a PDA is a marker for an increased risk of BPD. ${ }^{69}$ However, the large rate of crossover and the design of these studies makes it challenging to assess the risks and benefits of strategies designed to close the PDA.

\section{Supplemental oxygen}

For most infants, exposure to supplemental oxygen often begins in the delivery room. In a Cochrane meta-analysis of studies comparing resuscitation with $100 \%$ oxygen to resuscitation with room air in term and near term infants, resuscitation performed with room air resulted in lower mortality than in those resuscitated with $100 \%$ oxygen $(\mathrm{RR}=0.71]) .{ }^{70}$ However, among preterm infants the role of supplemental oxygen therapy in the delivery room is less clear. In a RCT of room air versus oxygen administration for the delivery room resuscitation of preterm infants less than 32 weeks gestation (ROAR study), there was no difference in the outcomes of BPD or death among infants treated with either room air, titrated oxygen therapy or those who received static $100 \%$ oxygen. ${ }^{71}$ Although the use of oxygen for preterm infants in the delivery room does not appear to influence the 
development of BPD, it would still appear prudent to limit the use of supplemental oxygen when possible.

Supplemental oxygen has been implicated as a potential toxin for the developing lung and brain. ${ }^{72}$ Infants who require high amounts of oxygen may represent a more ill group of infants for whom gas exchange is already impaired at the alveolar level; however, oxygen can also produce oxidative injury to capillary, endothelial and alveolar membranes. Prior studies have indicated that high levels of oxygen exposure result in increased polymorphonuclear cell migration, increased proteolysis and elevated levels of inflammatory cytokines. ${ }^{73,74}$ Yet, oxygen therapy is often necessary in premature infants in order to prevent hypoxemia and oxygen may be important for cell growth and development. In the Benefits Of Oxygen Saturation Targeting trial (BOOST-I), infants $<30$ weeks who were randomized to higher oxygen saturations (95-98\%) as compared to standard oxygen saturations (92-94\%) at 32 weeks corrected gestation, remained on oxygen therapy at 36 weeks corrected gestation more often (OR 1.40: 95\% CI 1.15, 1.70). However, there was no difference in the growth or development at 12 months between the two groups. ${ }^{75}$

The need for supplemental oxygen therapy can be a marker of severe illness and is therefore associated with an increased risk of BPD. In the SUPPORT trial, one arm of the study examined the effect of target ranges of oxygen saturations in extremely preterm infants. Infants who were randomized to lower oxygen saturations (85-89\%) as compared to infants who were randomized to higher oxygen saturations (91-95\%) had similar rates of BPD among survivors $48.5 \%$ vs $54.2 \%$ (RR $0.91(0.83-1.01)$ ). ${ }^{76}$ This would suggest that the role of oxygen in the development of BPD for preterm infants is linked to the severity of illness as compared to direct oxygen toxicity. Furthermore, the SUPPORT trial reported an increase in mortality in the lower oxygen saturation group.

\section{Vitamin A}

Vitamin A is involved in multiple activities at the cellular level including regulating gene transcription, signaling in embryonic development and as a potent antioxidant. These functions are likely impaired in premature infants who also exhibit vitamin A deficiency. Treatment with vitamin A replacement therapy decreases the risk of BPD or death by 36 weeks PMA in infants $<1000 \mathrm{~g}$ who remain on respiratory support at 24 hours of life (RR $0.89[0.80,0.99]) .{ }^{77}$ The supplementation was noted to increase serum vitamin A levels without increasing the risk of toxicity. The use of Vitamin A in very low birth weight infants has been hampered recently due to national shortages and lack of availability at many centers. $^{78}$

\section{Caffeine}

The use of caffeine for the treatment of apnea of prematurity has been demonstrated to decrease the risk of BPD, though the mechanisms of action are not clear. Caffeine has been shown to increase carbon dioxide chemoreceptor responsiveness, increase respiratory muscle performance and generally increase central nervous system excitability. ${ }^{79-81}$ In the Caffeine for Apnea of Prematurity (CAP) trial, the infants randomized to caffeine therapy had a lower incidence of BPD (36\% vs. 47\%, adjusted OR 0.64 (0.52-0.78)), as defined by oxygen need at 36 weeks PMA. ${ }^{82}$

\section{Sepsis and the systemic inflammatory response}

Sepsis and the systemic inflammatory response increase the likelihood of BPD in premature infants. Several pathogens have been associated with the development of BPD including Ureaplasma urealyticum, cytomegalovirus, and adenovirus. ${ }^{83-85}$ The direct role that these pathogens play in the development of BPD is unclear, but thought to be related to the 
systemic inflammatory response. The inflammatory response in the lung results in production of pro-inflammatory cytokines, migration of PMNs and changes in vascular permeability. ${ }^{86,87}$ The presence of these factors likely causes immediate damage to alveoli and capillaries, but also may be related to the long-term arrest of alveolarization seen in infants with BPD.

\section{Predictive models of BPD}

In the last decade, researchers have developed predictive models for long-term morbidities, such as neurodevelopmental impairment. Schmidt et al. ${ }^{88}$ examined the impact of BPD, brain injury, and severe ROP on 18-month outcomes and determined that the incidence of poor long-term outcomes increased with the presence of 1,2, or all 3 neonatal morbidities.. Tyson et al. ${ }^{89}$ examined infants in the NRN and determined that exposure to antenatal corticosteroids, female sex, singleton birth, and higher birth weight (per 100-g increment) were each associated with reductions in the risk of death and the risk of death or neurodevelopmental impairment. The authors developed a simple, Web-based predictive tool (www.nichd.nih.gov/neonatalestimates) that helps clinicians estimate the likelihood that intensive care will benefit individual infants.

Clinicians, parents, and researchers would benefit from an accurate predictive model of BPD risk based on readily available clinical information. Prediction scoring systems have been described for BPD and have included birth-weight, gestational age, sex, PDA, sepsis and exposure to mechanical ventilation, but until recently, have not been readily available or adopted. In many of these scoring systems death was not included as a competing outcome for BPD. ${ }^{90-92}$ Some included radiographs as part of the scoring system, which introduces subjectivity and reduces generalizability. ${ }^{93-96}$ Several used respiratory parameters that are not readily available to clinicians. ${ }^{97,98}$ In spite of generally good negative predictive values, the positive predictive values of these predictive models are low (range $65 \%$ to $75 \%$ ). ${ }^{93-100}$ Other significant problems were the absence of a contemporary cohort that included a high proportion of infants receiving antenatal corticosteroids and surfactant therapy. ${ }^{94}$ None examined the risk of BPD based on the NICHD severity based system.

An additional problem with previously reported analyses is a lack of detail regarding the change in BPD risk with advancing postnatal age.${ }^{90-92,94}$ Prior multivariable models included risk factors identifiable at birth, as well as exposures up to the time of diagnosis of $\mathrm{BPD}$, but do not include postnatal age. The inclusion of postnatal age allows for the variable contribution of risk factors over time as potential preventative or therapeutic strategies that may be employed to decrease the risk of BPD.

Laughon et al. recently developed a predictive model using data from the NICHD NRN Benchmarking Trial, which is available online at https://neonatal.rti.org. ${ }^{38}$ This model incorporates gestational age, birth weight, race and ethnicity, sex, respiratory support and fractional of inspired oxygen in a parsimonious model, providing estimates of severity of $\mathrm{BPD}$ or death by postnatal day. It is noteworthy that several previously described risk factors- PDA, NEC, sepsis and postnatal corticosteroids did not significantly improve the prediction of BPD after adjustment for the other six factors. For example, a white male infant born at 26 weeks (BW 750g) who at day 7 of life is on CPAP with an oxygen requirement of $35 \%$ has a $19.9 \%$ probability of having severe BPD, $34.2 \%$ for moderate BPD, $28.6 \%$ for mild BPD and $10.2 \%$ for no BPD. An important feature of this model is that the relative contribution of each predicting factor changes with increasing postnatal age. In postnatal day 1 and 3 models, gestational age provides the most information, while at later time points, mechanical ventilation conveys the most predictive information. 


\section{Conclusions}

The development of bronchopulmonary dysplasia is the result of the complex interactions between multiple perinatal and postnatal factors. Although predictive factors for BPD are easy to identify they are often difficult to modify. Early identification of infants at the greatest risk of developing BPD through the use of estimators and models may allow a targeted approach for reducing BPD in the future.

\section{Acknowledgments}

Dr. Laughon receives support from the U.S. government for his work in pediatric and neonatal clinical pharmacology (Government Contract HHSN267200700051C, PI: Benjamin under the Best Pharmaceuticals for Children's Act), and from NICHD (1K23HL092225-01).

\section{References}

1. Michael Cotten C, Oh W, McDonald S, et al. Prolonged hospital stay for extremely premature infants: risk factors, center differences, and the impact of mortality on selecting a best-performing center. J Perinatol. 2005; 25:650-5. [PubMed: 16079906]

2. Katz-Salamon M, Gerner EM, Jonsson B, Lagercrantz H. Early motor and mental development in very preterm infants with chronic lung disease. Arch Dis Child Fetal Neonatal Ed. 2000; 83:F1-6. [PubMed: 10873161]

3. McAleese KA, Knapp MA, Rhodes TT. Financial and emotional cost of bronchopulmonary dysplasia. Clinical pediatrics. 1993; 32:393-400. [PubMed: 8365073]

4. Gough A, Spence D, Linden M, Halliday HL, McGarvey L. General and Respiratory Health Outcomes in Adult Survivors of Bronchopulmonary Dysplasia: A Systematic Review. Chest. 2011

5. Hintz SR, Poole WK, Wright LL, et al. Changes in mortality and morbidities among infants born at less than 25 weeks during the post-surfactant era. Arch Dis Child Fetal Neonatal Ed. 2005; 90:F128-33. [PubMed: 15724036]

6. Berger TM, Bachmann II, Adams M, Schubiger G. Impact of improved survival of very low-birthweight infants on incidence and severity of bronchopulmonary dysplasia. Biol Neonate. 2004; 86:124-30. [PubMed: 15192303]

7. Northway WH, Rosan RC, Porter DY. Pulmonary Disease Following Respirator Therapy of Hyaline-Membrane Disease. New England Journal of Medicine. 1967; 276:357-68. [PubMed: 5334613]

8. Bancalari, E. Barotrauma to the lung. In: AM, editor. Advances in Perinatal Medicine. New York: Plenum; 1982.

9. Bancalari E, Gerhardt T. Bronchopulmonary dysplasia. Pediatric clinics of North America. 1986; 33:1-23. [PubMed: 3513095]

10. Coalson JJ, Winter V, deLemos RA. Decreased alveolarization in baboon survivors with bronchopulmonary dysplasia. American Journal of Respiratory \& Critical Care Medicine. 1995; 152:640-6. [PubMed: 7633720]

11. Jobe AJ. The new BPD: an arrest of lung development. Pediatric Research. 1999; 46:641-3. [PubMed: 10590017]

12. Stoelhorst GM, Rijken M, Martens SE, et al. Changes in neonatology: comparison of two cohorts of very preterm infants (gestational age <32 weeks): the Project On Preterm and Small for Gestational Age Infants 1983 and the Leiden Follow-Up Project on Prematurity 1996-1997. Pediatrics. 2005; 115:396-405. [PubMed: 15689337]

13. Wadhawan R, Vohr BR, Fanaroff AA, et al. Does labor influence neonatal and neurodevelopmental outcomes of extremely-low-birth-weight infants who are born by cesarean delivery? Am J Obstet Gynecol. 2003; 189:501-6. [PubMed: 14520225]

14. Jobe AH, Bancalari E. Bronchopulmonary dysplasia. Am J Respir Crit Care Med. 2001; 163:17239. [PubMed: 11401896] 
15. Ehrenkranz RA, Walsh MC, Vohr BR, et al. Validation of the National Institutes of Health consensus definition of bronchopulmonary dysplasia. Pediatrics. 2005; 116:1353-60. [PubMed: $16322158]$

16. Walsh MC, Yao Q, Gettner P, et al. Impact of a physiologic definition on bronchopulmonary dysplasia rates. Pediatrics. 2004; 114:1305-11. [PubMed: 15520112]

17. Natarajan G, Pappas A, Shankaran S, et al. Outcomes of extremely low birth weight infants with bronchopulmonary dysplasia: Impact of the physiologic definition. Early Hum Dev. 2012

18. Stewart A, Brion LP, Soll R. Diuretics for respiratory distress syndrome in preterm infants. Cochrane Database Syst Rev. 2011:CD001454. [PubMed: 22161366]

19. Massie SE, Tolleson-Rinehart S, DeWalt DA, Laughon MM, Powell LM, Price WA. Development of a proxy-reported pulmonary outcome scale for preterm infants with bronchopulmonary dysplasia. Health Qual Life Outcomes. 2011; 9:55. [PubMed: 21791099]

20. Fletcher, R.; Fletcher, S. Clinical Epidemiology. 4. Lippincott Williams \& Wilkins; 2005.

21. Rothman, K.; Greenland, S.; Lash, T. Modern Epidemiology. 3. Philadelphia, PA: Lippincott Williams \& Wilkins; 2008. p. 51-70.

22. Greenland S, Robins JM. Identifiability, exchangeability, and epidemiological confounding. International journal of epidemiology. 1986; 15:413-9. [PubMed: 3771081]

23. Bradford-Hill A. The Environment and Disease: Association or Causation? Proceedings of the Royal Society of Medicine. 1965; 58:295-300. [PubMed: 14283879]

24. Marshall DD, Kotelchuck M, Young TE, Bose CL, Kruyer L, O’Shea TM. Risk factors for chronic lung disease in the surfactant era: a North Carolina population-based study of very low birth weight infants. North Carolina Neonatologists Association. Pediatrics. 1999; 104:1345-50. [PubMed: 10585987]

25. Oh W, Poindexter BB, Perritt R, et al. Association between fluid intake and weight loss during the first ten days of life and risk of bronchopulmonary dysplasia in extremely low birth weight infants. J Pediatr. 2005; 147:786-90. [PubMed: 16356432]

26. Ambalavanan N, Van Meurs KP, Perritt R, et al. Predictors of death or bronchopulmonary dysplasia in preterm infants with respiratory failure. J Perinatol. 2008; 28:420-6. [PubMed: 18337740]

27. Rojas MA, Gonzalez A, Bancalari E, Claure N, Poole C, Silva-Neto G. Changing trends in the epidemiology and pathogenesis of neonatal chronic lung disease. The Journal of pediatrics. 1995; 126:605-10. [PubMed: 7699543]

28. Crowley P. The effects of corticosteroid administration before preterm delivery: an overview of the evidence from controlled trials. British journal of obstetrics and gynaecology. 1990; 97:11-25. [PubMed: 2137711]

29. Gilstrap LC, Christensen R, Clewell WH, et al. Effect of Corticosteroids for Fetal Maturation on Perinatal Outcomes. JAMA: The Journal of the American Medical Association. 1995; 273:413-8. [PubMed: 7823388]

30. Van Marter LJ. Maternal glucocorticoid therapy and reduced risk of bronchopulmonary dysplasia. Pediatrics (Evanston). 1990; 86:331-6.

31. Been JV, Zimmermann LJ. Histological chorioamnionitis and respiratory outcome in preterm infants. Arch Dis Child Fetal Neonatal Ed. 2009; 94:F218-25. [PubMed: 19131431]

32. Dempsey E. Outcome of neonates less than 30 weeks gestation with histologic chorioamnionitis. American journal of perinatology. 2005; 22:155-9. [PubMed: 15838750]

33. Richardson BS. Preterm histologic chorioamnionitis: impact on cord gas and $\mathrm{pH}$ values and neonatal outcome. American journal of obstetrics and gynecology. 2006; 195:1357-65. [PubMed: 16677589]

34. Mu S-C. Impact on neonatal outcome and anthropometric growth in very low birth weight infants with histological chorioamnionitis. Journal of the Formosan Medical Association. 2008; 107:30410. [PubMed: 18445544]

35. De Felice C. Histologic chorioamnionitis and severity of illness in very low birth weight newborns. Pediatric critical care medicine. 2005; 6:298-302. [PubMed: 15857528] 
36. Hartling L, Liang Y, Lacaze-Masmonteil T. Chorioamnionitis as a risk factor for bronchopulmonary dysplasia: a systematic review and meta-analysis. Arch Dis Child Fetal Neonatal Ed. 2012; 97:F8-F17. [PubMed: 21697236]

37. Bose C, Van Marter LJ, Laughon M, et al. Fetal growth restriction and chronic lung disease among infants born before the 28th week of gestation. Pediatrics. 2009; 124:e450-8. [PubMed: 19706590]

38. Laughon MM, Langer JC, Bose CL, et al. Prediction of bronchopulmonary dysplasia by postnatal age in extremely premature infants. Am J Respir Crit Care Med. 2011; 183:1715-22. [PubMed: 21471086]

39. Stoll BJ, Hansen NI, Bell EF, et al. Neonatal outcomes of extremely preterm infants from the NICHD Neonatal Research Network. Pediatrics. 2010; 126:443-56. [PubMed: 20732945]

40. Lemons JA, Bauer CR, Oh W, et al. Very Low Birth Weight Outcomes of the National Institute of Child Health and Human Development Neonatal Research Network, January 1995 Through December 1996. Pediatrics. 2001; 107:e1. [PubMed: 11134465]

41. Charafeddine L, D’Angio CT, Phelps DL. Atypical chronic lung disease patterns in neonates. Pediatrics. 1999; 103:759-65. [PubMed: 10103299]

42. Panickar J, Scholefield H, Kumar Y, Pilling DW, Subhedar NV. Atypical chronic lung disease in preterm infants. Journal of perinatal medicine. 2004; 32:162-7. [PubMed: 15085893]

43. Choi CW, Kim BI, Koh YY, Choi JH, Choi JY. Clinical characteristics of chronic lung disease without preceding respiratory distress syndrome in preterm infants. Pediatr Int. 2005; 47:72-9. [PubMed: 15693871]

44. Choi CW, Kim BI, Park JD, Koh YY, Choi JH, Choi JY. Risk factors for the different types of chronic lung diseases of prematurity according to the preceding respiratory distress syndrome. Pediatr Int. 2005; 47:417-23. [PubMed: 16091080]

45. Streubel AH, Donohue PK, Aucott SW. The epidemiology of atypical chronic lung disease in extremely low birth weight infants. J Perinatol. 2008; 28:141-8. [PubMed: 18059466]

46. Kobaly K, Schluchter M, Minich N, et al. Outcomes of extremely low birth weight $(<1 \mathrm{~kg})$ and extremely low gestational age ( $<28$ weeks) infants with bronchopulmonary dysplasia: effects of practice changes in 2000 to 2003. Pediatrics. 2008; 121:73-81. [PubMed: 18166559]

47. Merrill JD, Ballard RA, Cnaan A, et al. Dysfunction of pulmonary surfactant in chronically ventilated premature infants. Pediatric research. 2004; 56:918-26. [PubMed: 15496605]

48. Muscedere JG, Mullen JB, Gan K, Slutsky AS. Tidal ventilation at low airway pressures can augment lung injury. Am J Respir Crit Care Med. 1994; 149:1327-34. [PubMed: 8173774]

49. Meredith KS, deLemos RA, Coalson JJ, et al. Role of lung injury in the pathogenesis of hyaline membrane disease in premature baboons. Journal of applied physiology: respiratory, environmental and exercise physiology. 1989; 66:2150-8.

50. Avery ME, Tooley WH, Keller JB, et al. Is chronic lung disease in low birth weight infants preventable? A survey of eight centers. Pediatrics. 1987; 79:26-30. [PubMed: 3797169]

51. Van Marter LJ, Allred EN, Pagano M, et al. Do clinical markers of barotrauma and oxygen toxicity explain interhospital variation in rates of chronic lung disease? The Neonatology Committee for the Developmental Network. Pediatrics. 2000; 105:1194-201. [PubMed: 10835057]

52. Walsh M, Laptook A, Kazzi SN, et al. A cluster-randomized trial of benchmarking and multimodal quality improvement to improve rates of survival free of bronchopulmonary dysplasia for infants with birth weights of less than 1250 grams. Pediatrics. 2007; 119:876-90. [PubMed: 17473087]

53. Leone TA, Rich W, Finer NN. A survey of delivery room resuscitation practices in the United States. Pediatrics. 2006; 117:e164-75. [PubMed: 16452326]

54. Morley CJ, Davis PG, Doyle LW, Brion LP, Hascoet JM, Carlin JB. Nasal CPAP or intubation at birth for very preterm infants. N Engl J Med. 2008; 358:700-8. [PubMed: 18272893]

55. Finer NN, Carlo WA, Duara S, et al. Delivery room continuous positive airway pressure/positive end-expiratory pressure in extremely low birth weight infants: a feasibility trial. Pediatrics. 2004; 114:651-7. [PubMed: 15342835]

56. Halliday HL, Ehrenkranz RA, Doyle LW. Early ( $<8$ days) postnatal corticosteroids for preventing chronic lung disease in preterm infants. Cochrane database of systematic reviews (Online).

2009:CD001146. [PubMed: 19160190] 
57. Halliday HL, Ehrenkranz RA, Doyle LW. Late ( $>7$ days) postnatal corticosteroids for chronic lung disease in preterm infants. Cochrane database of systematic reviews (Online). 2009:CD001145. [PubMed: 19160189]

58. Doyle LW, Davis PG, Morley CJ, McPhee A, Carlin JB. Low-dose dexamethasone facilitates extubation among chronically ventilator-dependent infants: a multicenter, international, randomized, controlled trial. Pediatrics. 2006; 117:75-83. [PubMed: 16396863]

59. Doyle LW, Davis PG, Morley CJ, McPhee A, Carlin JB. Outcome at 2 years of age of infants from the DART study: a multicenter, international, randomized, controlled trial of low-dose dexamethasone. Pediatrics. 2007; 119:716-21. [PubMed: 17403842]

60. Doyle LW, Halliday HL, Ehrenkranz RA, Davis PG, Sinclair JC. Impact of postnatal systemic corticosteroids on mortality and cerebral palsy in preterm infants: effect modification by risk for chronic lung disease. Pediatrics. 2005; 115:655-61. [PubMed: 15741368]

61. Schmidt B, Davis P, Moddemann D, et al. Long-term effects of indomethacin prophylaxis in extremely-low-birth-weight infants. N Engl J Med. 2001; 344:1966-72. [PubMed: 11430325]

62. Brown ER. Increased risk of bronchopulmonary dysplasia in infants with patent ductus arteriosus. The Journal of pediatrics. 1979; 95:865-6. [PubMed: 490263]

63. 〈PDAandBPD_Clyman.pdf >.

64. Clyman R, Cassady G, Kirklin JK, Collins M, Philips JB 3rd. The role of patent ductus arteriosus ligation in bronchopulmonary dysplasia: reexamining a randomized controlled trial. The Journal of pediatrics. 2009; 154:873-6. [PubMed: 19324366]

65. Fowlie PW, Davis PG. Prophylactic intravenous indomethacin for preventing mortality and morbidity in preterm infants. Cochrane Database Syst Rev. 2002:CD000174. [PubMed: 12137607]

66. Cooke L, Steer P, Woodgate P. Indomethacin for asymptomatic patent ductus arteriosus in preterm infants. Cochrane Database Syst Rev. 2003:CD003745. [PubMed: 12804488]

67. Shah SS, Ohlsson A. Ibuprofen for the prevention of patent ductus arteriosus in preterm and/or low birth weight infants. Cochrane Database Syst Rev. 2006:CD004213. [PubMed: 16437478]

68. Benitz WE. Treatment of persistent patent ductus arteriosus in preterm infants: time to accept the null hypothesis? J Perinatol. 2010; 30:241-52. [PubMed: 20182439]

69. Benitz WE. Patent ductus arteriosus: to treat or not to treat? Archives of Disease in Childhood Fetal and Neonatal Edition. 2012; 97:F80-F2. [PubMed: 22174019]

70. Tan A, Schulze A, O'Donnell CP, Davis PG. Air versus oxygen for resuscitation of infants at birth. Cochrane Database Syst Rev. 2005:CD002273. [PubMed: 15846632]

71. Rabi Y, Singhal N, Nettel-Aguirre A. Room-Air Versus Oxygen Administration for Resuscitation of Preterm Infants: The ROAR Study. Pediatrics. 2011; 128:e374-e81. [PubMed: 21746729]

72. Saugstad OD. Chronic lung disease: the role of oxidative stress. Biol Neonate. 1998; 74 (Suppl 1): 21-8. [PubMed: 9730588]

73. Ogihara T, Hirano K, Morinobu T, et al. Raised concentrations of aldehyde lipid peroxidation products in premature infants with chronic lung disease. Arch Dis Child Fetal Neonatal Ed. 1999; 80:F21-5. [PubMed: 10325806]

74. Delacourt C, d'Ortho MP, Macquin-Mavier I, et al. Oxidant-antioxidant balance in alveolar macrophages from newborn rats. The European respiratory journal: official journal of the European Society for Clinical Respiratory Physiology. 1996; 9:2517-24. [PubMed: 8980963]

75. Askie LM, Henderson-Smart DJ, Irwig L, Simpson JM. Oxygen-saturation targets and outcomes in extremely preterm infants. N Engl J Med. 2003; 349:959-67. [PubMed: 12954744]

76. Carlo WA, Finer NN, Walsh MC, et al. Target ranges of oxygen saturation in extremely preterm infants. N Engl J Med. 2010; 362:1959-69. [PubMed: 20472937]

77. Tyson JEWL, Oh W, Kennedy KA, Mele L, Ehrenkranz RA, Stoll BJ, Lemons JA, Stevenson DK, Bauer CR, Korones SB, Fanaroff AA. Vitamin A supplementation for extremely-low-birth-weight infants. New England Journal of Medicine. 1999; 340:1962-8. [PubMed: 10379020]

78. Kaplan HC. Understanding variation in vitamin A supplementation among NICUs. Pediatrics (Evanston). 2010; 126:e367-73.

79. Bairam A. Interactive ventilatory effects of two respiratory stimulants, caffeine and doxapram, in newborn lambs. Biology of the neonate. 1992; 61:201-8. [PubMed: 1610947] 
80. Kassim Z. Effect of caffeine on respiratory muscle strength and lung function in prematurely born, ventilated infants. European journal of pediatrics. 2009; 168:1491-5. [PubMed: 19271237]

81. Henderson-Smart DJ. Prophylactic methylxanthines for endotracheal extubation in preterm infants. Cochrane database of systematic reviews. 2010:CD000139.

82. Schmidt B, Roberts RS, Davis P, et al. Caffeine therapy for apnea of prematurity. N Engl J Med. 2006; 354:2112-21. [PubMed: 16707748]

83. Hannaford K, Todd DA, Jeffery H, John E, Blyth K, Gilbert GL. Role of ureaplasma urealyticum in lung disease of prematurity. Arch Dis Child Fetal Neonatal Ed. 1999; 81:F162-7. [PubMed: 10525015]

84. Ollikainen J, Heiskanen-Kosma T, Korppi M, Katila ML, Heinonen K. Clinical relevance of Ureaplasma urealyticum colonization in preterm infants. Acta Paediatr. 1998; 87:1075-8. [PubMed: 9825976]

85. Sawyer MH, Edwards DK, Spector SA. Cytomegalovirus infection and bronchopulmonary dysplasia in premature infants. Am J Dis Child. 1987; 141:303-5. [PubMed: 3028127]

86. Wynn J, Cornell TT, Wong HR, Shanley TP, Wheeler DS. The host response to sepsis and developmental impact. Pediatrics. 2010; 125:1031-41. [PubMed: 20421258]

87. Cornell TT, Wynn J, Shanley TP, Wheeler DS, Wong HR. Mechanisms and regulation of the geneexpression response to sepsis. Pediatrics. 2010; 125:1248-58. [PubMed: 20478944]

88. Schmidt B, Asztalos EV, Roberts RS, Robertson CM, Sauve RS, Whitfield MF. Impact of bronchopulmonary dysplasia, brain injury, and severe retinopathy on the outcome of extremely low-birth-weight infants at 18 months: results from the trial of indomethacin prophylaxis in preterms. Jama. 2003; 289:1124-9. [PubMed: 12622582]

89. Tyson JE, Parikh NA, Langer J, Green C, Higgins RD. Intensive care for extreme prematurity-moving beyond gestational age. The New England journal of medicine. 2008; 358:1672-81. [PubMed: 18420500]

90. Ryan SW, Nycyk J, Shaw BN. Prediction of chronic neonatal lung disease on day 4 of life. Eur J Pediatr. 1996; 155:668-71. [PubMed: 8839722]

91. Subhedar NV, Hamdan AH, Ryan SW, Shaw NJ. Pulmonary artery pressure: early predictor of chronic lung disease in preterm infants. Archives of disease in childhood. 1998; 78:F20-4. [PubMed: 9536835]

92. Romagnoli C, Zecca E, Tortorolo L, Vento G, Tortorolo G. A scoring system to predict the evolution of respiratory distress syndrome into chronic lung disease in preterm infants. Intensive Care Med. 1998; 24:476-80. [PubMed: 9660264]

93. Toce SS, Farrell PM, Leavitt LA, Samuels DP, Edwards DK. Clinical and roentgenographic scoring systems for assessing bronchopulmonary dysplasia. American journal of diseases of children (1960). 1984; 138:581-5. [PubMed: 6720645]

94. Corcoran JD, Patterson CC, Thomas PS, Halliday HL. Reduction in the risk of bronchopulmonary dysplasia from 1980-1990: results of a multivariate logistic regression analysis. European journal of pediatrics. 1993; 152:677-81. [PubMed: 8404973]

95. Noack G, Mortensson W, Robertson B, Nilsson R. Correlations between radiological and cytological findings in early development of bronchopulmonary dysplasia. European journal of pediatrics. 1993; 152:1024-9. [PubMed: 8131804]

96. Yuksel B, Greenough A, Karani J. Prediction of chronic lung disease from the chest radiograph appearance at seven days of age. Acta Paediatr. 1993; 82:944-7. [PubMed: 8111175]

97. Bhutani VK, Abbasi S. Relative likelihood of bronchopulmonary dysplasia based on pulmonary mechanics measured in preterm neonates during the first week of life. The Journal of pediatrics. 1992; 120:605-13. [PubMed: 1552402]

98. Kim YD, Kim EA, Kim KS, Pi SY, Kang W. Scoring method for early prediction of neonatal chronic lung disease using modified respiratory parameters. Journal of Korean medical science. 2005; 20:397-401. [PubMed: 15953859]

99. Sinkin RA, Cox C, Phelps DL. Predicting risk for bronchopulmonary dysplasia: selection criteria for clinical trials. Pediatrics. 1990; 86:728-36. [PubMed: 2235227] 
100. Rozycki HJ, Narla L. Early versus late identification of infants at high risk of developing moderate to severe bronchopulmonary dysplasia. Pediatric pulmonology. 1996; 21:345-52. [PubMed: 8927460] 


\section{KEYPOINTS}

- Bronchopulmonary dysplasia, also called chronic lung disease, is the most common serious pulmonary morbidity in premature infants.

- Premature infants with BPD have life-long morbidities including an increased risk of cerebral palsy and mental retardation.

- The incidence of BPD is inversely related to gestational age and birth weight.

- Prediction of BPD using parsimonious models by postnatal day is now possible. 


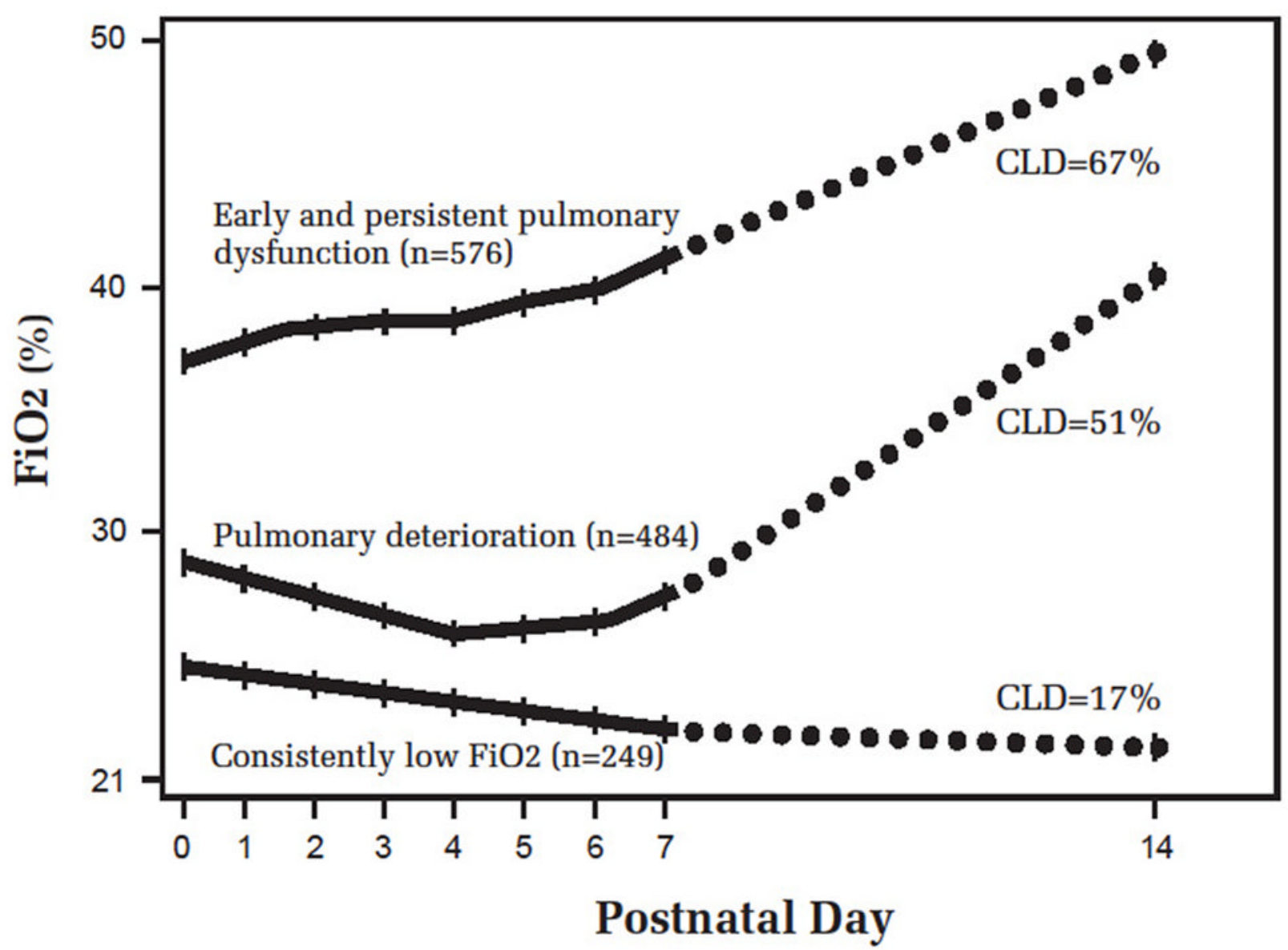

FIGURE 1.

Risk of chronic lung disease (or bronchopulmonary dysplasia) among 1340 extremely low gestational age newborns with 3 patterns of respiratory disease. Reprinted with permission from the American Academy of Pediatrics from Laughon et al. Pediatrics 2009. 123. 11241131. 
Table 1

NICHD severity-based definition of BPD

\begin{tabular}{|c|c|c|c|}
\hline $\begin{array}{l}\text { Gestational age at } \\
\text { birth }\end{array}$ & Mild BPD & Moderate BPD & Severe BPD \\
\hline$<32$ weeks & $\begin{array}{c}\text { Room air at } 36 \text { wk PMA or } \\
\text { discharge }{ }^{*}\end{array}$ & $\begin{array}{c}<30 \% \text { oxygen at } 36 \text { wk PMA or } \\
\text { discharge }\end{array}$ & $\begin{array}{l}230 \% \text { oxygen and/or positive pressure at } \\
\qquad 36 \text { wk PMA }\end{array}$ \\
\hline$\geq 32$ weeks & $\begin{array}{c}\text { Room air by } 56 \text { d postnatal age } \\
\text { or discharge }\end{array}$ & $\begin{array}{c}<30 \% \text { oxygen at } 56 \mathrm{~d} \text { postnatal age or } \\
\text { discharge }\end{array}$ & $\begin{array}{l}30 \% \text { oxygen and/or positive pressure at } \\
56 \mathrm{~d} \text { postnatal age or discharge }\end{array}$ \\
\hline
\end{tabular}

* All categories require treatment with $>21 \%$ for at least 28 days, then assessment at PMA/postnatal day or discharge whichever comes first

Adapted from Jobe \& Bancalari, American Journal of Respiratory and Critical Care Medicine, 2001. 